\title{
COVID-19-Associated Guillain-Barre Syndrome: Atypical Para-infectious Profile, Symptom Overlap, and Increased Risk of Severe Neurological Complications
}

\author{
Mayanja M. Kajumba ${ }^{1}$ (D) Brad J. Kolls ${ }^{2,3,4} \cdot$ Deborah C. Koltai $^{2,3,5} \cdot$ Mark Kaddumukasa $^{6} \cdot$ Martin Kaddumukasa $^{6}$. \\ Daniel T. Laskowitz ${ }^{2,3,4}$
}

Accepted: 16 November 2020 / Published online: 21 November 2020

(C) Springer Nature Switzerland AG 2020

\begin{abstract}
The concurrence of COVID-19 with Guillain-Barre syndrome (GBS) can increase the likelihood of neuromuscular respiratory failure, autonomic dysfunction, and other life-threatening symptoms. Currently, very little is known about the underlying mechanisms, clinical course, and prognostic implications of comorbid COVID-19 in patients with GBS. We reviewed COVID-19associated GBS case reports published since the outbreak of the pandemic, with a database search up to August 2020, including a manual search of the reference lists for additional relevant cases. Fifty-one (51) case reports of COVID-19 patients (aged 2384 years) diagnosed with GBS in 11 different countries were included in this review. The results revealed atypical manifestations of GBS, including para-infectious profiles and onset of GBS without antecedent COVID-19 symptoms. Although all tested patients had signs of neuroinflammation, none had SARS-CoV-2 in the cerebrospinal fluid (CSF), and only four (4) patients had antiganglioside antibodies. The majority had a 1- to 10-day time interval between the onset of COVID-19 and GBS symptoms, and many had a poor outcome, with 20 out of the 51 (39.2\%) requiring mechanical ventilation, and two deaths within 12 to $24 \mathrm{~h}$. The atypical manifestations of COVID-19-associated GBS, especially the para-infectious profile and short time interval between the onset of the COVID-19 and GBS symptoms, increase the likelihood of symptom overlap, which can complicate the treatment and result in worsened disease progression and/or higher mortality rates. Inclusion of a neurological assessment during diagnosis of COVID-19 might facilitate timely identification and effective management of the GBS symptoms and improve treatment outcome.
\end{abstract}

Keywords SARS-CoV-2 $\cdot$ COVID-19 $\cdot$ Atypical $\cdot$ Guillain-Barre $\cdot$ Para-infectious $\cdot$ Prognosis

This article is part of the Topical Collection on COVID-19

Mayanja M. Kajumba

kajumba@chuss.mak.ac.ug; kajumbamayanja@gmail.com

1 Department of Mental Health and Community Psychology, School of Psychology, Makerere University, P. O. Box,

7062 Kampala, Uganda

2 Duke Division of Global Neurosurgery and Neurology, Department of Neurosurgery, Duke University Medical Center, Box 3807, Durham, NC 27705, USA

3 Department of Neurology, Duke University School of Medicine, Durham, NC, USA

4 Neuroscience Medicine, Duke Clinical Research Institute, $300 \mathrm{~W}$ Morgan St, Durham, NC 27701, USA

5 Department of Psychiatry and Behavioral Sciences, DUMC, Duke University School of Medicine, Box 3119, Trent Drive,

Durham, NC, USA

6 Department of Medicine, School of Medicine, College of Health Sciences, Makerere University, P.O. Box 7072, Kampala, Uganda

\section{Introduction}

The recent outbreak of the coronavirus disease 2019 (COVID19) has caused an unprecedented worldwide pandemic characterized by an overwhelming health burden and serious socioeconomic consequences. This disease is typified by respiratory symptoms, ranging from mild flu-like symptoms to a severe highly lethal pneumonia $[1,2]$. The current coronavirus pandemic is caused by the newly identified severe acute respiratory syndrome coronavirus 2 (SARS-CoV-2), which is a highly pathogenic coronavirus that is associated with rapid infectivity rates. The structure of SARS-CoV-2 and its mechanism of infection are similar to those associated with other coronaviruses, including the severe acute respiratory syndrome coronavirus (SARS-CoV) and Middle East respiratory syndrome coronavirus (MERS-CoV) $[1,3]$. In this regard, SARS-CoV-2 has a 75-80\% identical genome sequence with MERS-CoV and SARS-CoV [4, 5], but it is far more 
transmissible [6] and causes more deaths than these two coronaviruses.

Although the neuropathogenic mechanisms associated with SARS-CoV-2 infection are still unclear, a recent study found that 78/214 (36.4\%) of COVID-19 patients presented with neurological symptoms [7]. Among the most devastating neurological conditions triggered by SARS-CoV-2 is Guillain-Barre syndrome (GBS) $[2,8,9]$. GBS is a rare autoimmune disorder [10] characterized by inflammatory demyelinating and/or axonal neuropathy, resulting in rapidly progressive paralysis with either reduced or absent reflexes [11], which may also be associated with cranial neuropathy and pain [12]. One of the prominent assumptions about the underlying pathological mechanisms of GBS is molecular mimicry, a process in which antibodies formed against the virus or other pathogens bind to gangliosides on the surface membranes of peripheral motor and sensory neurons and cause an immune-mediated damage to the myelin sheath and/or axons [13] (Fig. 1). The SARS-CoV-2 infection triggers an adaptive immune response in which $\mathrm{T}$ cell-B cell interactions result in the production of SARS-CoV-2specific antibodies [14], but a similarity in viral and ganglioside peptide sequences or structure (molecular mimicry) [15] can result in a loss of self-tolerance [16]. Under these circumstances, the gangliosides, which are predominantly located on the membranes of neurons and the Schwann cells [17], which form the myelin sheath, may act as receptors for antiganglioside antibodies, which neutralize the neurons' complement inhibitory activity [18] and turn them into targets for an autoimmune-mediated destruction of myelin sheaths or axons [16, 19] (Fig. 1). Depending on the nature of the damage, an individual may experience either the demyelinating or axonal GBS subtype, which not only differ in the symptom manifestations but also in the likelihood of recovery [20].

GBS has a worldwide annual incidence of 1.2-2.3 per 100,000 [25] that increases to 3.3 per 100,000 in adults over 50 years [26], and it is associated with significant complications, mortality, and severe residual functional disability [27, 28]. Of particular interest during the COVID-19 pandemic, GBS is one of the leading causes of neuromuscular respiratory failure, necessitating mechanical ventilation in approximately 17 to $30 \%$ of afflicted patients [29]. Respiratory failure is most common in patients with a rapid rate of disease progression, autonomic dysfunction, bulbar dysfunction, or bilateral facial weakness [30]. Since respiratory failure is also a prominent feature of COVID-19, the GBS-COVID-19 comorbidity could exacerbate severe respiratory dysfunction and increase the overall symptom burden and need for mechanical ventilation.

One of the most concerning features of COVID-19associated GBS is the recently reported para-infectious profile [31], which involves concurrent manifestation of symptoms for these two conditions. Typically, GBS is regarded as a post- infectious disorder, with two-thirds of patients experiencing respiratory or gastrointestinal infection 2 to 3 weeks prior to the onset of GBS symptoms $[32,33]$. The para-infectious profile suggests that the onset of the symptoms occurs during active infection, and the overlap between the COVID-19 and GBS respiratory symptoms can complicate treatment and potentially lead to higher mortality. Thus, the quest for identifying the best medical countermeasures or procedures for improving COVID-19 treatment outcome requires understanding of the onset and manifestation of the GBS-related neurological symptoms and how they influence the prognosis of COVID-19 patients. Most of the evidence to date is based on individual case reports, which may not give a complete picture of the manifestations and extent of the detrimental effects of COVID-19-associated GBS. The purpose of the current review was to evaluate the case reports of COVID19-associated GBS published since the outbreak of the pandemic, with the goal of assessing the onset and manifestation of COVID-19-associated GBS, its symptom profiles, neuroinflammatory mediators, and the prognosis of patients with comorbid COVID-19 and GBS.

\section{Methods}

\section{Case Reports Identification}

We searched PubMed/MEDLINE, ScienceDirect, and Google Scholar for case reports of COVID-19-associated GBS, published since the coronavirus outbreak in December 2019, as well as and Journal pre-proof articles. The search terms included "COVID-19," "GBS," "SARS-COV-2," "Case Reports," "Guillain-Barré syndrome," "para-infectious," and "post-infectious." The search yielded a total of 51 COVID-19positive patients with a clinical diagnosis of GBS.

\section{Inclusion Criteria}

For inclusion into the study, the cases must have been diagnosed with COVID-19 or found to be SARS-CoV-2 positive. The GBS symptoms had to have manifested during or after the documentation of SARS-CoV-2 infection and thus not be a preexisting condition, and the diagnosis must have been confirmed through a peer-review process of the publishing journal. All the identified cases were adults (age $>18$ years), and the reviewed cases met the established criteria for the diagnosis of GBS [34, 35]. In particular, the diagnoses were based on compatible clinical features and clinical course associated with muscle weakness and absent or depressed deep tendon reflexes; supportive cerebrospinal fluid analysis with evidence of cytoalbuminological dissociation; and electrodiagnostic evidence of acute demyelination (decreased motor nerve conduction velocity, prolonged distal motor latency, increased $\mathrm{F}$ 


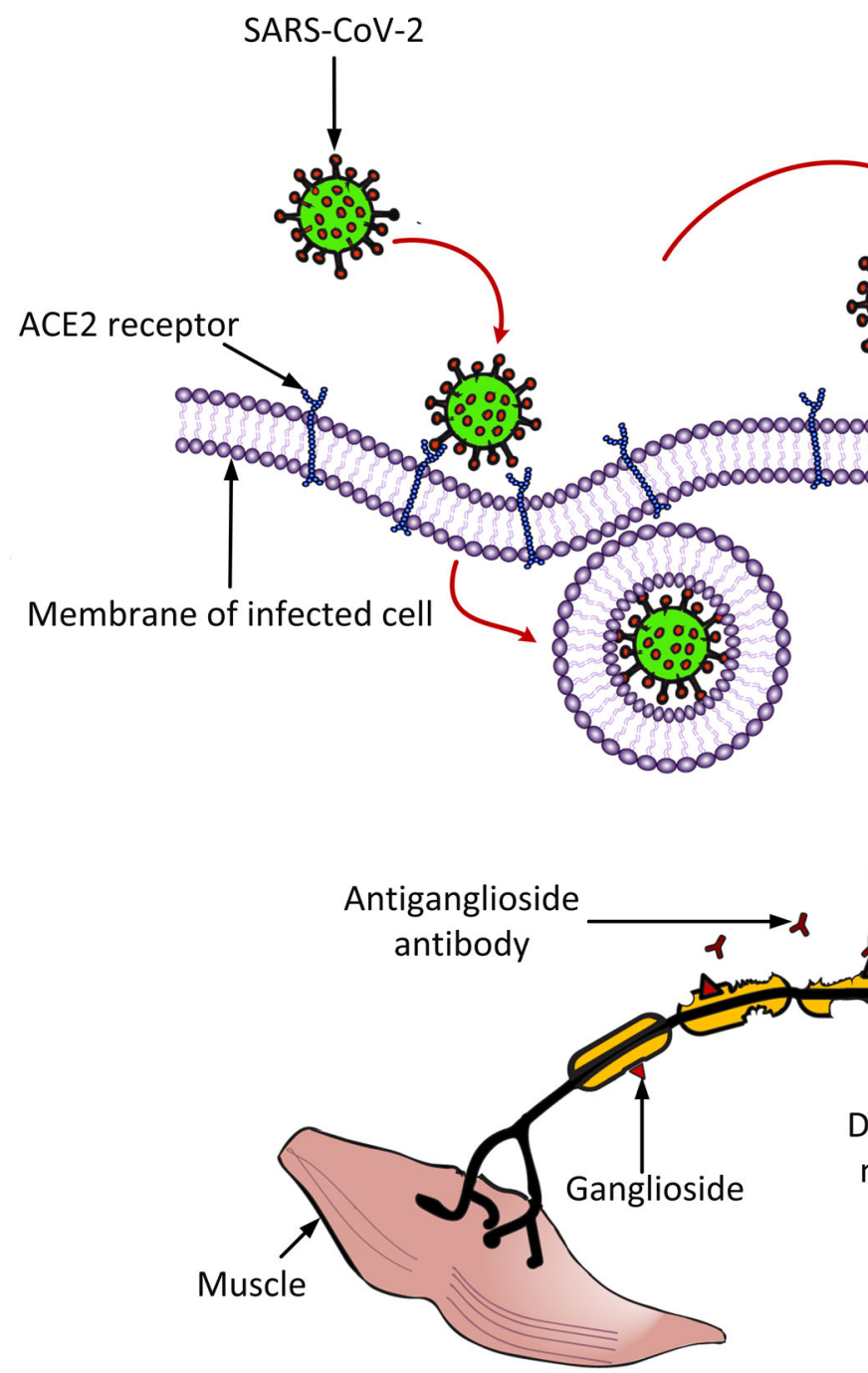

Fig.1 A schematic representation of the likely pathophysiology of COVID-19-associated GBS. SARS-COV-2 has a high affinity for the angiotensin-converting enzyme 2 (ACE2) receptor [21], located on nasal and oral mucosa [22], neurons, glia cells, and blood vessels of the central nervous system [23, 24]. During an infection, SARS-COV-2 binds this receptor and is endocytosed. Due to similarity in the peptide sequences or epitopes of SARS-Cov-2 and gangliosides (molecular mimicry), the

wave latency, conduction blocks, and temporal dispersion) or axonal GBS variant (reduced distal motor and/or sensory amplitudes or transient motor nerve conduction block). Furthermore, all the cases had to have been published or approved for publication and presented in English.

\section{Data Extraction}

For each case report, we extracted information about (1) the patient's neurological symptoms, (2) time interval between the onset of COVID-19 and GBS symptoms, (3) GBS subtype, (4) medical history, (5) results of nasopharyngeal swab and CSF analysis for SARS-CoV-2 infection, (6) CSF protein level, (7) evidence of pleocytosis, (8) antiganglioside antibodies formed against the virus, through the T Cell-B cell interactions, may bind the gangliosides located on the peripheral neurons. This may result in an autoimmune response that destroys the myelin and/or axons. The demyelination or axonal damage disrupts neural transmission, which causes the GBS symptoms such as muscle weakness, paralysis, coordination problems, breathing difficulties, and autonomic dysfunction

antibodies, (9) GBS manifestation profile, and (10) prognostic indicators.

\section{Results}

Our search yielded a total of 51 case reports of COVID-19associated GBS with exclusion of related diagnoses, from 11 different countries including Italy $(N=15)[2,8,12,36-41]$, Spain $(N=8)[9,11,42-46]$, the USA $(N=9)[22,47-53]$, Iran $(N=5)[32,54-56]$, Germany $(N=3)$ [57-59], the UK $(N=3)$ [60-62], France $(N=4)$ [63-65], Canada $(N=1)$ [66], China $(N=1)$ [31], Morocco $(N=1)$ [67], and Switzerland 
$(N=1)$ [40]. Figure 2 shows the patient distribution by country.

\section{Demographic and Clinical Characteristics of the COVID-19-Associated GBS Cases}

The information about sociodemographic characteristics and the medical history of the patients is summarized in Table 1, and the data on the onset of COVID-19 and GBS symptoms and laboratory test results are presented in Table 2. Table 3 shows the neurological manifestation of COVID-19-asociated GBS subtypes, while Fig. 3 is a schematic illustration of the atypical manifestation of this disease, its clinical course, and prognosis. Overall, we identified 51 COVID-19-associated GBS cases which we included in this study. However, among these patients, there were five (5) cases who met the GBS symptom criteria, but did not have documentation of nerve conduction study results $[9,47,50,52]$; as we could not conclude whether they involved demyelination or axonal neuropathy, these cases were not included in the classification of GBS subtypes.

The patients were predominantly male $(76.5 \%)$. Overall, the patients were elderly with a median of 60 years and mean age ( \pm standard deviation) of $58.3 \pm 12.8$ years: $63.3 \pm 11.6$ for females and $56.7 \pm 12.9$ years for males. The overall age ranges $23-84$ years. Preexisting medical conditions were reported by $45.1 \%$ of the patients and mainly involved hypertension with or without comorbid conditions, followed by type 2 diabetes mellitus.
In the majority of the cases (54.9\%), the time interval between the onset of COVID-19 and GBS symptoms was 1 to 10 days, with a median of 10 and interquartile range of 12 days. Of the 51 patients, 49 tested positive for COVID19, while two (2) had negative results, but tested positive for SARS-CoV-2 antibodies, suggesting an onset of GBS after resolution of the antecedent infection in these two cases. However, for all the 32 patients tested, there was no evidence of SARS-CoV-2 in the CSF. Of the 42 patients tested, 34 had elevated CSF protein, but none of the patients tested had an increase in the number of lymphocytes in the in the CSF (pleocytosis). Eight patients had normal protein levels (CSF protein may remain normal when tested acutely in GBS). Of the 30 patients tested, only four (4) had antiganglioside antibodies, including GM2 IgM, GD3 IgM, and GT1b IgG for one, and GM2 IgG/IgM for another patient with acute inflammatory demyelinating polyneuropathy (AIDP), GD1b-IgG for a patient with Miller-Fisher Syndrome (MFS), and GD1b for one patient diagnosed with acute motor axonal neuropathy (AMAN).

Table 3 shows the neurological manifestation of COVID19-asociated GBS. In the cases in which electrodiagnostic data were available $(N=46)$, the majority, $30(65.23 \%)$ presented with acute inflammatory demyelinating polyneuropathy (AIDP), followed in 7 (15.23\%) patients by acute motor-sensory axonal neuropathy (AMSAN), 3 (6.52\%) with Miller-Fisher syndrome (MFS), 3 (6.52\%) with an AIDP-MFS overlap, and 1 (2.17\%) with acute motor axonal neuropathy (AMAN). The results also revealed rare GBS
Fig. 2 Number of COVID-19associted GBS cases identified from each country. The number of COVID-19-associated GBS cases were highest in Italy, the USA, Spain, and Iran, which by August 2020 were among the countries hardest hit by the COVID-19 pandemic

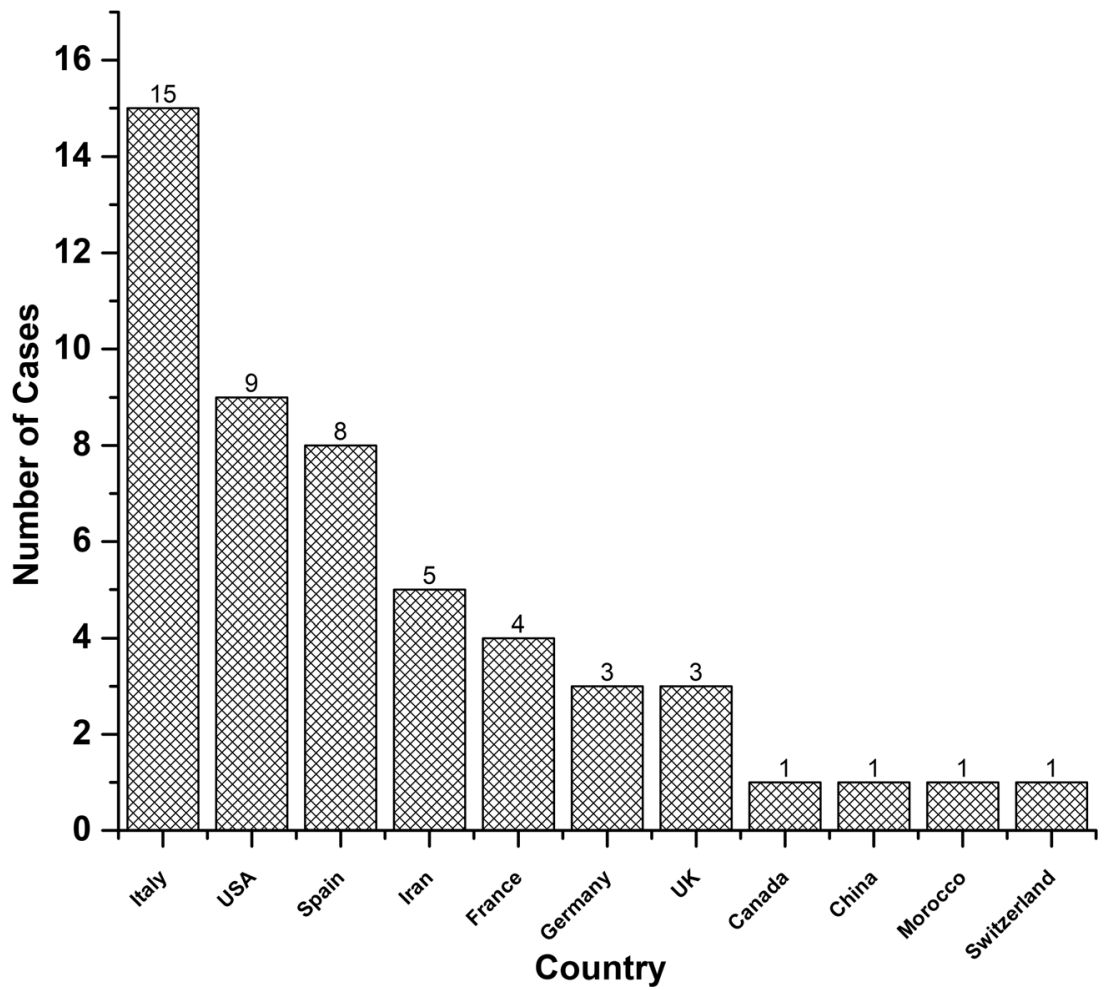

SN Comprehensive Clinical Medicine 
Table 1 Sociodemographic characteristics of COVID-19. associated GBS cases published during the pandemic outbreak (January to August 2020)

\begin{tabular}{|c|c|c|c|c|}
\hline Sex & $\begin{array}{l}\text { Frequency } \\
(\%)\end{array}$ & $\begin{array}{l}\text { Mean Age } \\
\text { (years) }\end{array}$ & $\begin{array}{l}\text { Median Age } \\
\text { (years) }\end{array}$ & $\begin{array}{l}\text { Range } \\
\text { (years) }\end{array}$ \\
\hline Female $(N=12)$ & $12(23.53)$ & $63.33 \pm 11.59$ & 66.50 & $35-77$ \\
\hline Male $(N=39)$ & 39 (76.47) & $56.69 \pm 12.90$ & 58.00 & $23-84$ \\
\hline Total & $51(100)$ & $58.25 \pm 12.81$ & 60.00 & $23-84$ \\
\hline \multicolumn{5}{|l|}{ Age (years) } \\
\hline$\leq 49$ & $11(21.57)$ & & & \\
\hline $50-59$ & $13(25.49)$ & & & \\
\hline $60-69$ & $16(31.37)$ & & & \\
\hline $70-79$ & $10(19.61)$ & & & \\
\hline $80-89$ & $1(1.96)$ & & & \\
\hline Total & $51(100)$ & & & \\
\hline \multicolumn{5}{|l|}{ Medical history } \\
\hline Breast cancer & $1(1.96)$ & & & \\
\hline Bronchial asthma & $1(1.96)$ & & & \\
\hline Hypertension & $8(15.69)$ & & & \\
\hline Hypertension \& obesity & $1(1.96)$ & & & \\
\hline Hypertension \& psoriasis & $1(1.96)$ & & & \\
\hline Hypertension \& AAA & $1(1.96)$ & & & \\
\hline Hypertension \& CAD & $1(1.96)$ & & & \\
\hline $\begin{array}{l}\text { Hypertension, dyslipidemia, BPH, \& } \\
\text { AAA }\end{array}$ & $1(1.96)$ & & & \\
\hline Infantile strabismus & $1(1.96)$ & & & \\
\hline Obesity & $1(1.96)$ & & & \\
\hline Rheumatoid arthritis & $1(1.96)$ & & & \\
\hline Sinusitis & $1(1.96)$ & & & \\
\hline Type 2 diabetes mellitus & $4(7.84)$ & & & \\
\hline None & $16(31.37)$ & & & \\
\hline Not reported & $12(23.53)$ & & & \\
\hline Total & $51(100)$ & & & \\
\hline
\end{tabular}

$A A A$ abdominal aortic aneurysm, $C A D$ coronary artery disease, $B P H$ benign prostatic hyperplasia variants including polyneuritis cranialis (PNC) and bilateral facial diplegia without blink reflexes, both of which involved cranial neuropathies. The atypical symptoms observed in this study include cognitive disturbance in the form of psychomotor agitation with confusion, dizziness with or without headache, and partial loss of consciousness, which could be a sign of possible COVID-19-associated central nervous system involvement. The neurological features indicated signs of demyelination, axonal damage, enhancement of spinal nerve roots, and impaired sensory and motor impulse transmission. Table 4 summarizes the associations between clinical GBS features and respiratory failure.

The majority of the cases $(48 / 51 ; 94.12 \%)$ developed COVID-19 symptoms ranging from mild to severe and had either a post-infectious $(36 / 51 ; 70.59 \%)$ or para-infectious $(12 / 51 ; 23.53 \%)$ profile, while $3 / 51(5.88 \%)$ were asymptomatic for COVID-19 but developed GBS symptoms. For 30/51 $(58.82 \%)$ of the cases, including $11(36.67 \%)$ with para- infectious and 19 (63.33\%) with a post-infectious profile, the time interval between the onset of COVID-19 and GBS symptoms was $1-12$ days. Due to the small sample size $(N=48)$, the analysis yielded wide $95 \%$ confidence intervals, which reduces the degree of precision of the estimate, but both the odds ratios and our general observation indicate that the 112 day onset interval was associated with a higher likelihood for respiratory failure, admission into the intensive care unit, and use of mechanical ventilation compared to the onset GBS after a time interval longer than 12 days since the onset of COVID-19 symptoms, OR $=2.6$ (95\% CI 0.74-9.12) Among the 20 patients put on mechanical ventilation, 15 (75\%) had a time interval of 1 to 12 days between the onset of COVID-19 and GBS symptoms, and overall, the odds were higher for the para-infectious, compared to the post-infectious profiles, $\mathrm{OR}=1.57$ (95\% CI 0.42-5.85). Furthermore, 50.0\% of patients with a para-infectious, and $38.89 \%$ with a postinfectious profile, were put on mechanical ventilation, with 
Table 2 Time interval between the onset of COVID-19 and GBS symptoms and laboratory test results

\begin{tabular}{|c|c|c|c|c|}
\hline \multirow[t]{2}{*}{ Time Interval (days) } & \multirow[t]{2}{*}{ Frequency $(\%)$} & \multirow[t]{2}{*}{ Median ( \pm IQR $)$} & Interquartile range & \multirow[t]{2}{*}{ Range (days) } \\
\hline & & & 25 th $\quad 75$ th & \\
\hline$<1$ & $2(3.92)$ & $10.00 \pm 12.00$ & 18.00 & $0-21$ \\
\hline $1-10$ & $28(54.90)$ & & & \\
\hline $11-20$ & $13(25.49)$ & & & \\
\hline $21-30$ & $8(15.69)$ & & & \\
\hline Total & $51(100.00)$ & & & \\
\hline Laboratory tests & Patients tested $(N)$ & Status/results & Frequency $(\%)$ & GBS subtype \\
\hline SARS-CoV-2 for COVID-19 & 51 & & & \\
\hline Viral Test & & Positive & $49(96.08)$ & All \\
\hline Serology Test & & Positive & $2(3.92)$ & AIDP \\
\hline SARS-CoV-2 in CSF & 32 & Negative & $32(100)$ & All \\
\hline \multirow[t]{4}{*}{ Anti-gang. antibodies } & 30 & Absent & $26(86.67)$ & All \\
\hline & & GD1b IgG & $2(6.67)$ & AMAN, MFS \\
\hline & & GM2 IgG/IgM & $1(3.33$ & GBS* \\
\hline & & GM2 IgM, GD3-IgM, GT1b & $1(3.33)$ & AIDP \\
\hline \multirow[t]{2}{*}{ CSF proteins } & 42 & Elevated & $34(80.95)$ & All \\
\hline & & Normal & $8(19.05)$ & AIDP, AIDP-MFS, AMSAN \\
\hline Pleocytosis & 37 & Absent & $37(100)$ & All \\
\hline
\end{tabular}

$G B S^{*}$ GBS not categorized due to absence of nerve conduction studies, Anti-gang antigangliosides

one patient in each category respectively dying within 24 and $12 \mathrm{~h}$ after onset of the GBS symptoms. Overall, the individuals with a para-infectious profile and those with a postinfectious profile but with a short latency between the onset of COVID-19 and the GBS symptoms were more likely to have a poor prognosis. Figure 3 illustrates the temporal relationship and clinical course of COVID-19-associated GBS.

\section{Discussion}

Our study reviewed COVID-19-associated GBS case reports published since the outbreak of the pandemic, with the main objective of examining the relationship between SARS-CoV2 -associated onset and manifestation of GBS, its neuroinflammatory features, and the prognosis of the patients presenting with para- or post-infectious profiles. The results indicate that SARS-CoV-2 infection is associated with the onset of GBS, including AIDP, AMSAN, AMAN, and MFS subtypes. We also found a rare AIDP-MFS overlap and atypical GBS variants including polyneuritis cranialis and bilateral facial diplegia without blink reflexes, which are cranial neuropathies that do not meet the diagnostic criteria for MFS or other GBS subtypes with known cranial nerve involvement. The bilateral facial diplegia without blink reflexes has not been previously reported but may be similar to the rare GBS variant with prominent facial diplegia that manifests with paresthesia [68, 69]. The majority of the cases reviewed presented with demyelinating neuropathy, which is consistent with
GBS associated with the other six pathogens, including Zika virus, hepatitis E virus, Mycoplasma pneumoniae, Campylobacter jejuni, Cytomegalovirus, and Epstein-Barr virus [12]. Of note, these results are not consistent with a recent review of an unspecified number of cases by Gupta et al. [70], which suggested that acute motor axonal neuropathy (AMAN) and AMSAN are the most common GBS subtypes associated with COVID-19.

The inconsistency in the proportions of GBS subtypes could be attributed to possible genetic variation, with evidence indicating a higher prevalence of AIDP in the western world, while AMAN and AMSAN are more prevalent in Asian and Southern and Central American populations [71]. Interestingly however, in this study, AMAN accounted for only $2.17 \%$ of the cases, which is even lower than the rare MFS subtype that accounted for $6.52 \%$ of the cases in this study. The rare AIDP-MFS overlap also accounted for $6.52 \%$, which when added to the atypical bilateral facial diplegia without blink reflexes, and polyneuritis cranialis, suggests a potential for more cranial involvement of COVID-19associated GBS, compared to GBS associated with other infections. The potential for greater cranial involvement of COVID-19-associated GBS is also reflected in the atypical neurological symptoms such as dizziness, alterations in level of consciousness, psychomotor agitation, and headache observed in this review. Although signs of vestibular dysfunction such as dizziness or disorientation have been previously reported in some GBS patients, they are rare and associated cranial neuropathy [72]. It is more likely that these symptoms 
Table 3 The neurological manifestations of COVID-19-associated GBS

\begin{tabular}{|c|c|c|c|c|}
\hline Subtype & Neuromuscular symptoms & Sensory symptoms & Autonomic dysfunction & Neurophysiological features \\
\hline \multirow[t]{11}{*}{$\operatorname{AIDP}(65.23 \%)$} & - Ascending quadriparesis & - Anosmia and ageusia & - Voiding dysfunction & - Delayed or prolonged distal motor latencies \\
\hline & - Areflexia & - Dysesthesia/paresthesia & - Constipation & - Reduced muscle action potential amplitude \\
\hline & - Impaired movement & $\begin{array}{l}\text { - Vibratory and proprioceptive } \\
\text { loss }\end{array}$ & - Respiratory failure & • Reduced motor conduction velocities \\
\hline & - Facial palsy/diplegia & $\begin{array}{l}\text { - Lost light touch and pinprick } \\
\text { sensation }\end{array}$ & - Dysphagia & - Absent sensory nerve action potentials \\
\hline & $\begin{array}{l}\text { - Oropharyngeal/hypoglossal } \\
\text { palsy }\end{array}$ & $\begin{array}{l}\text { - Stocking-and-glove } \\
\text { hypesthesia }\end{array}$ & - Irregular heartbeat & - Conduction blocks \\
\hline & • Ophthalmoparesis & - Distal allodynia & - Increased blood pressure & - Absent $\mathrm{F}$ waves \\
\hline & - Psychomotor agitation & - Low back and/or thoracic pain & - Multiple organ failure & - Absent H-reflex \\
\hline & - Fatigue & • Headache & $\begin{array}{l}\text { Hypotension/hyperten- } \\
\text { sion }\end{array}$ & - A sural sparing pattern \\
\hline & - Decreased muscle tone & - Confusion & & $\begin{array}{l}\text { - Brainstem and cervical meningeal } \\
\text { enhancement }\end{array}$ \\
\hline & $\begin{array}{l}\text { - Ascending } \\
\text { quadriplegia/paraplegia }\end{array}$ & - Dizziness & & $\begin{array}{l}\text { - Cranial neuritis (in nerves III, V, VI, VII, } \\
\text { and VIII) }\end{array}$ \\
\hline & & - Loss of consciousness & & $\begin{array}{l}\text { - Radiculitis \& plexitis on the brachial \& } \\
\text { lumbar plexus }\end{array}$ \\
\hline \multirow[t]{10}{*}{ MFS $(6.52 \%)$} & - Hyporeflexia or areflexia & - Anosmia and ageusia & - Dysphagia & $\begin{array}{l}\text { - Enhancement with lesion of cranial nerve } \\
\text { (CN) III }\end{array}$ \\
\hline & - Ataxia & - Paresthesia & & \\
\hline & - Facial palsy & - Sensory loss/numbness & & \\
\hline & - Ophthalmoparesis & - Blurry vision/double vision & & \\
\hline & - Oculomotor palsy & - Dizziness on walking & & \\
\hline & - Pupillary dysfunction & - Headache & & \\
\hline & - Eyelid ptosis & & & \\
\hline & - Impaired eye movement & & & \\
\hline & • Hypoglossal palsy & & & \\
\hline & - Dysphonia & & & \\
\hline $\begin{array}{l}\text { AIDP-MFS } \\
\qquad(6.52 \%)\end{array}$ & $\begin{array}{l}\text { - Overlap of AIPD \& MFS } \\
\text { symptoms }\end{array}$ & & & \\
\hline \multirow{6}{*}{$\begin{array}{l}\text { AMSAN } \\
\quad(15.23 \%)\end{array}$} & - Ascending quadriparesis & - Paresthesia & - Gastroplegia & - Reduced muscle action potential amplitude \\
\hline & - Quadriplegia/paraplegia & - Vibratory and Light touch loss & - Respiratory failure & - Absent sensory nerve action potential \\
\hline & - Facial paresis or palsy & - Neck or mastoid pain & • Dysphagia & - Decrease in facial nerve cMAP amplitude \\
\hline & - Areflexia & - Sensory ataxia & & - Reduced sensory action potential amplitudes \\
\hline & - Ataxia & & & - Reduced motor action potential amplitudes \\
\hline & • Hypoglossal palsy & & & $\begin{array}{l}\text { - Bilateral facial nerve enhancement } \\
\text { - Enhanced caudal nerve roots }\end{array}$ \\
\hline \multirow[t]{3}{*}{$\operatorname{AMAN}(2.17 \%)$} & - Progressive tetraparesis & & • Tachycardia & - Reduced compound motor action potentials \\
\hline & - Tachycardia & & $\begin{array}{l}\text { - Absent heart rate } \\
\text { variability }\end{array}$ & \\
\hline & - Absent heart rate variability & & • Dysphagia & \\
\hline \multirow[t]{2}{*}{ PNC (2.17\%) } & - Diplopia & - Ageusia & & \\
\hline & $\begin{array}{l}\text { - Abducens nerve palsy } \\
\text { - Areflexia }\end{array}$ & & & \\
\hline $\operatorname{FDBR} *(2.17 \%)$ & $\begin{array}{l}\text { - Bilateral facial nerve palsy } \\
\text { - Unresponsive blink reflex }\end{array}$ & & & \\
\hline
\end{tabular}

$A I D P$ acute inflammatory demyelinating polyneuropathy, $A M S A N$ acute motor-sensory axonal neuropathy, $M F S$ Miller-Fisher syndrome, $A M A N$ acute motor axonal neuropathy, $P N C$ polyneuritis cranialis, $F D B R^{*}$ facial diplegia without blink reflex

are related to COVID-19 since they are seen in many COVID19 patients who do not develop GBS [73, 74].

Although neurological symptoms were previously reported in severe COVID-19 cases [75], in this study, we found that GBS can also occur among patients who experience mild or no prior COVID-19 symptoms, and the manifestation involves the typical post-infectious and atypical parainfectious profiles. The patients categorized as parainfectious had a concurrent manifestation of COVID-19 and
GBS symptoms, while in the case of the post-infectious profile, the GBS symptoms occurred after resolution of the COVID-19 symptoms. Typically, GBS is a post-infectious condition with symptom onset for $76 \%$ of the patients occurring in about 4 weeks after the preceding respiratory or gastrointestinal infection [76]. The para-infectious profile is an atypical feature, which was only recently reported among patients infected with Zika virus [77]. In this study, 83.3\% of the para-infectious, and $50 \%$ of the post-infectious cases, 
experienced an onset of GBS between 1 and 10 days, after the onset of COVID-19 symptoms. This is consistent with the previous evidence indicating an average time interval of 5 to 10 days between the onset of the COVID-19 symptoms and GBS $[12,57]$, but the post-infectious manifestation is contrary to the finding that the mean COVID-19 recovery time is 10 to 21 days [78]. The finding that $50 \%$ of the post-infectious GBS cases occurred before the expected time of COVID-19 recovery suggests that some of the patients in this category could still be in the active infection phase. Indeed, apart from two patients who tested negative for SARS-CoV-2 but positive for its antibodies, all the patients tested for the virus at the onset of GBS symptoms had positive results. Furthermore, some patients (e.g., in Tiet \& Alshaikh, 2020) categorized as postinfectious still had some mild COVID-19 symptoms such as cough and continued to test positive for SARS-CoV-2 weeks after the GBS diagnosis. This suggests that patients with seemingly resolved, mild, or unnoticeable COVID-19 symptoms may fit the post-infectious profile, while still in an active infection phase, and put into question the categorization of
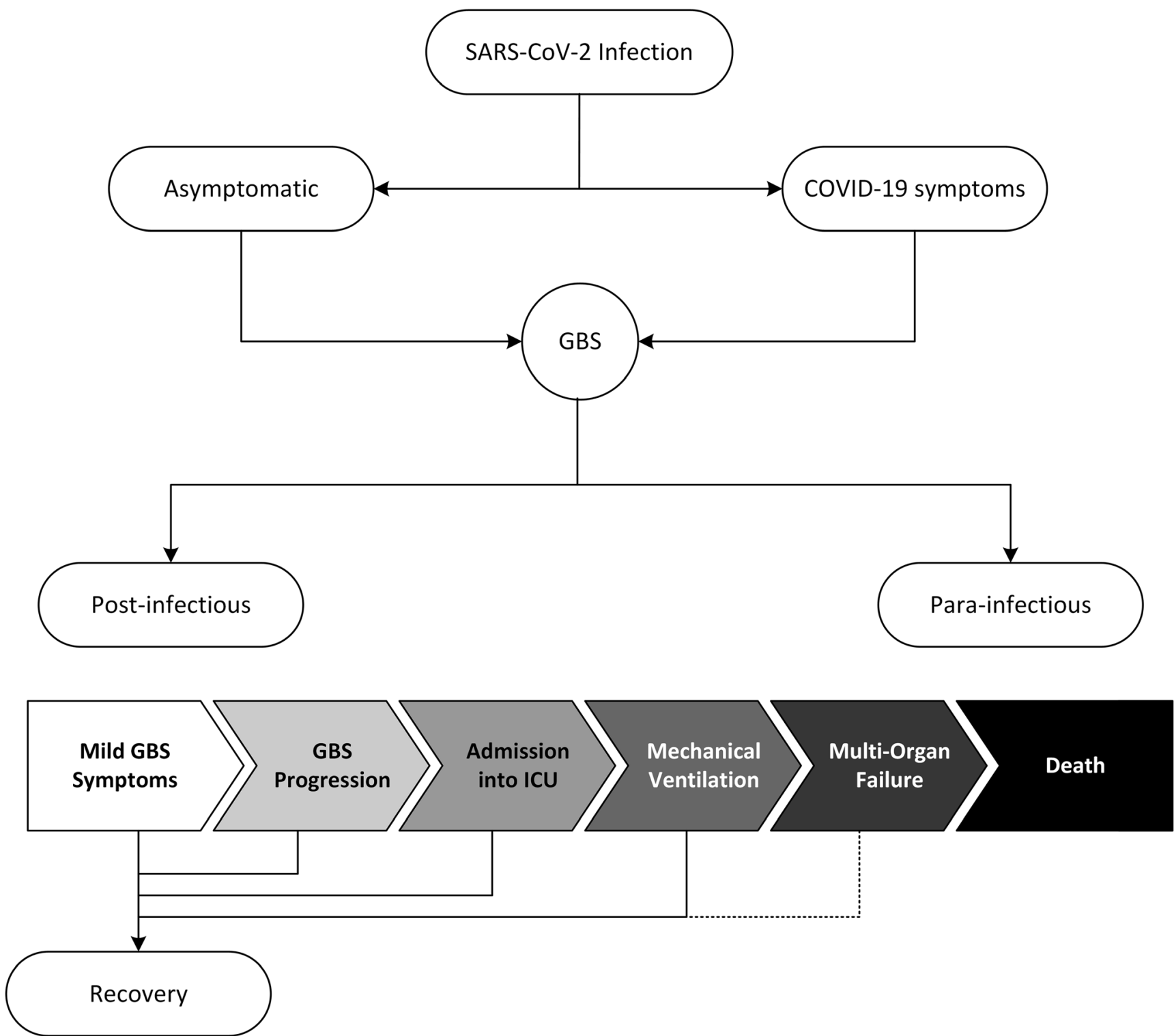

Fig. 3 The atypical manifestation and prognosis of COVID-19associated GBS. The results revealed that following SARS-CoV-2 infection, patients can experience GBS with or without developing COVID-19 symptoms. The GBS can manifest as a para-infectious profile, characterized by onset of symptoms during active SARS-CoV-2 infection and a COVID-19-GBS symptom overlap, while the post-infectious profile involves onset of GBS symptoms after recovering from the COVID-19.
However, some of the post-infectious profile patients may still test positive for SARS-COV-2 at the onset of GBS symptoms. The outcome ranged from mild to severe GBS symptoms, requiring admission into intensive care units, mechanical ventilation, prolonged stay in hospital, or discharge with severe residual or permanent disability, with the parainfectious profile having a higher likelihood for poor functional outcomes, due to the COVID-19-GBS symptom overlap 
Table 4 Association between COVID-19-GBS onset interval, manifestation profiles, and respiratory dysfunction

\begin{tabular}{|c|c|c|c|c|c|c|}
\hline \multirow{2}{*}{$\begin{array}{l}\text { COVID-19-GBS } \\
\text { onset interval }\end{array}$} & \multicolumn{3}{|c|}{ Manifestation profile } & \multicolumn{3}{|c|}{ Respiratory failure } \\
\hline & Freq $(\%)$ & $\begin{array}{l}\text { Para-infe. } \\
\text { freq }(\%)\end{array}$ & $\begin{array}{l}\text { Post-infe. } \\
\text { freq }(\%)\end{array}$ & $\begin{array}{l}\text { Yes freq } \\
(\%)\end{array}$ & $\begin{array}{l}\text { No freq } \\
(\%)\end{array}$ & OR (95\%CI) \\
\hline $1-12$ days & $30(58.82)$ & $11(36.67)$ & $19(63.33)$ & $15(50.00)$ & $15(50.00)$ & $2.6(0.74,9.12)$ \\
\hline$>12$ days & $18(35.29)$ & $1(5.56)$ & $17(94.44)$ & $5(27.78)$ & $13(72.22)$ & \\
\hline None & $3(5.88)$ & & & & $3(100)$ & \\
\hline Total & $51(100)$ & & & & & \\
\hline \multicolumn{7}{|c|}{ Manifestation profile } \\
\hline Para-infectious & $12(25 \%)$ & & & $6(50.00)$ & $6(50.00)$ & $1.57(0.42,5.85)$ \\
\hline Post-infectious & $36(75 \%)$ & & & $14(38.89)$ & $22(61.11)$ & \\
\hline Total & $48(100 \%)$ & & & & & \\
\hline
\end{tabular}

OR odds ratio, $C I$ confidence interval, Infe infectious, Freq frequency
COVID-19-associated GBS patients on the basis of the resolution of the antecedent symptoms. A more accurate categorization may require laboratory analysis to confirm the serological status and whether or not the patient is still in the active infection phase and has the potential to develop symptoms associated with the antecedent infection.

An accurate identification and categorization of GBS patients is very important, since the para-infectious profile is associated with a concurrent manifestation of COVID-19 and GBS symptoms, which can complicate the treatment and may be associated with a worse prognosis. Indeed, in this study, the patients with a para-infectious profile and those with a post-infectious profile but with a short time interval between the onset of COVID-19 and the GBS symptoms were more likely to have a poor prognosis. The link between the short duration and disease severity is illustrated by our observation that $75 \%$ of the patients admitted into intensive care units or put on mechanical ventilation had a 1- to 12-day COVID-19-GBS symptom onset interval. With this short time interval, a symptom overlap was more likely, and owing to the fact that COVID-19 mainly affects the respiratory system the higher incidence of pulmonary complications, and respiratory failure in particular, is a likely occurrence. The symptom overlap may also account for the finding that these patients experienced various serious complications including progressive muscle weakness and paralysis, which in some cases spread to involve the thoracic, cranial, and abdominal regions, resulting in some atypical signs of autonomic dysfunction such as irregular heartbeat, increased blood pressure, cardiac arrest, voiding dysfunction, constipation, respiratory failure, and multi-organ failure. Some of these patients remained in intensive care units for several weeks, others were discharged into inpatient rehabilitation centers, whereas others were able to go home but with lingering neurological symptoms. One of the patients died within $12 \mathrm{~h}$ after the onset of GBS-related bulbar symptoms [9] and another within $24 \mathrm{~h}$ due to progressive respiratory failure [2]. These findings highlight the potential devastating nature of the concurrent manifestation of COVID-19 and GBS symptoms. The short time interval of 1 to 10 days in this study, and 5 to 10 days in the previous studies $[12,57]$ as the duration between the onset of COVID-19 and GBS symptoms for majority of the patients, suggests that a para-infectious profile is the most likely manifestation of COVID-19-associated GBS. This is not only indicative of a potential for a poor prognosis due to symptom overlap, but also underscores the value of timely identification of neurological symptoms as part of the COVID-19 diagnostic process and specialized care for the patients with concurrent GBS symptoms.

In this study, we hypothesized that cerebrospinal fluid analysis might not only be helpful in aiding the diagnosis of COVID-19-associated GBS, but could also have some prognostic implications. The results revealed that none of the patients with reported CSF analysis had SARS-CoV-2 in the CSF, the majority of tested patients did not have antiganglioside antibodies, and most of the reviewed cases had raised protein levels in the CSF without pleocytosis (albuminocytological dissociation). Albuminocytological dissociation is a typical characteristic of GBS, found in about $90 \%$ of patients [79], and could be an important biomarker in ruling out differential diagnoses and in offering insight about the prognosis. In particular, the increase in CSF protein concentration may indicate the extent of active damage to the myelin, disease progression, and treatment response [80]. It is believed to be a consequence of antibody-mediated molecular mimicry mechanisms responsible for the erosion of the myelin sheath proteins from the axons [66], with an increase in the protein levels as evidence of the progression of demyelination [79] or other neuronal damage.

Interestingly, no antiganglioside antibodies were identified for the majority of the cases in this study, except for four patients, including one with GBS* who had anti-GM2 IgG/ 
IgM and another with AIDP variant with anti-GM2 IgM, antiGD3 IgM, and anti-GT1b IgG. The third patient with MFS had GD1b-IgG, while the fourth patient with the AMAN subtype also had GD1b. Elevated of anti-GM2 IgG/IgM is a rare occurrence in GBS but may be found in different subtypes with clinical heterogeneity of $\operatorname{IgM}$, while $\operatorname{IgG}$ is predominantly associated with cranial GBS variants, especially in patients presenting with oculomotor and vestibular dysfunction, characterized by dizziness [72]. However, in this study, neither the anti-GM2 IgG/IgM- nor the anti-GM2 IgM-positive patients had signs of cranial neuropathy, but both experienced autonomic dysfunction and were put on mechanical ventilation. The GD1b-IgG antibodies are formed against specific gangliosides on the axonal membranes [70] and thus are an atypical occurrence for MFS, which is known to mainly involve antiGQ1b in over $90 \%$ of the patients [81] and anti-GT1a antibodies that target gangliosides on oculomotor nerves and muscle spindles [13], as well as neuromuscular junctions of cranial nerves, an underlying mechanism for ophthalmoplegia. However, evidence suggests that anti-GQ1b and anti-GT1a antibodies can also react with GD1b gangliosides [19], which may in part explain the reported GD1b-IgG antibodies in this study. The presence of antibodies is consistent with the assumption that the mechanisms for the onset of GBS could involve neuroimmunological responses to the infection, especially molecular mimicry. Further support for the immunemediated neuropathogenesis of GBS comes from the observation in this study that most of the patients improved in response to immunoglobulin therapy.

On the other hand, the absence of antiganglioside antibodies in $86.7 \%$ of the tested patients suggests that nonimmunologic mechanisms such as direct infection of the nervous system could also be involved in the onset of GBS symptoms. On the basis of absent antibodies, Lantos et al. [48] hypothesized that viral neurotropism may play a role in mediating GBS symptoms. However, the absence of a single patient with SARS-CoV-2 in the CSF in our study does not support the assumption of direct infection of the nervous system in the pathogenesis of GBS. Supporting evidence for this assumption comes from results of a study by Steininger et al. [82] indicating that the DNA of cytomegalovirus (CMV), which is the most common antecedent viral infection, was detected in the CSF of GBS patients, especially at the early stage of illness. Another study by Kuijf et al. [83] with a larger sample and comparable assay characteristics found CMV DNA in the CSF of one GBS patient. There is also a recent report of a COVID-19 patient who did not have SARS-CoV-2 RNA in the nasopharyngeal swab but did have it in the CSF [84], and SARS-CoV-2 was also found in the brain tissue of a confirmed case of COVID-19 [85]. This evidence suggests that the absence of SARS-CoV-2 RNA in the CSF should not necessarily rule out the possibility for direct viral involvement in the etiology of GBS and other neurological disorders.
Indeed, there is evidence to suggest that CSF analysis may be complicated by the decrease in the viral load to undetectable levels, before the onset of the neurological symptoms [86], and the currently available real-time reverse-transcription polymerase chain reaction (rRT-PCR) only has about $60 \%$ sensitivity $[86,87]$. These might not be the only possible explanations for the absence of SARS-CoV-2 in the CSF of all the tested GBS patients in our study, and we propose further research to elucidate on this phenomenon and its implication on the prognosis of GBS.

A major limitation of our study is that, given the concurrent manifestation of the novel COVID-19 and GBS, especially for the para-infectious cases and those with a short duration between the onset of the two conditions, it remains possible that some COVID-19 symptoms could be attributed to GBS and vice versa, since both diseases affect the respiratory system. Some cases did not have all the required laboratory and neurological tests due to the overwhelming nature of the COVID19 pandemic and the stress it exerts on the hospital environment, logistical challenges, and the demand the large patient numbers exert on the medical personnel and system. Some of the patients were reported to have been in critical condition, which also prevented the conduction of electrodiagnostic tests. Such cases without results of nerve conduction were not categorized into GBS subtypes, since it was not possible to confirm whether the symptoms were due to demyelination or axonal damage. Furthermore, there were variations in the reporting format for each patient and some case reports missed some vital information. Further research with standardized study protocols could offer more insight into the underlying neuropathological mechanisms, atypical manifestation, and prognosis of COVID-19-associated GBS.

\section{Conclusions}

Evidence from this study suggests that SARS-COV-2 is a potential trigger of GBS, which not only manifests in patients with severe but also those with mild or absent prior COVID19 symptoms. Although GBS is typically regarded as a postinfectious neurological disorder, a large number of COVID19 patients present with an atypical para-infectious profile, and the majority of cases, including those with a postinfectious profile, have a short time latency between the onset of COVID-19 and GBS symptoms. This short time interval increases the likelihood for symptomatic overlap between para-infectious manifestations and a COVID-19-GBS, which not only complicates treatment but could also result in a poor prognosis characterized by severe autonomic dysfunction in the form of respiratory failure, heart failure, gastroplegia, multiple organ failure, and other signs of severe neuromuscular weakness or paralysis. These severe symptoms increase the odds for admission into the intensive care unit, need for 
mechanical ventilation, extended recovery period, higher mortality rate, and permanent disability. Thus, given the high infectibility rates of the novel SARS-COV-2, COVID-19associated GBS should be a major public health concern. GBS symptoms can progress very rapidly, and in our study, the two fatalities occurred within 12 to $24 \mathrm{~h}$ mainly caused respiratory failure and multi-organ failure. Paying particular attention to potential signs of GBS among COVID-19 patients and intervening at an early stage may improve treatment outcomes and minimize on morbidity, disease burden, and fatalities. Our findings suggest that inclusion of neurological assessment in the COVID-19 diagnostic process for timely identification and effective symptom management may yield better treatment outcomes. Although the exact relationship between the novel COVID-19 and comorbid GBS remains incompletely defined, systematic follow-up of the patients could aid in the quick identification of relapse cases, given that some patients continue to test positive for SARS-CoV-2 after a prolonged period of time.

Authors' Contributions All authors contributed to the review of the cases, critically revised all the previous versions, and approved the final manuscript.

Data Availability Not applicable.

\section{Compliance with Ethical Standards}

Conflict of Interest The authors declare that they have no conflict of interest.

Ethics approval Not applicable

Consent to Participate Not applicable; we reviewed cases from published literature.

Consent for Publication All authors have approved the publication of this work as submitted.

Code Availability Not applicable.

\section{References}

1. Li YC, Bai WZ, Hashikawa T. The neuroinvasive potential of SARS-CoV2 may play a role in the respiratory failure of COVID19 patients. J Med Virol. 2020;92:552-5. https://doi.org/10.1002/ jmv. 25728 .

2. Alberti P, Beretta S, Piatti M, Karantzoulis A, Piatti ML, Santoro P, et al. Guillain-Barré syndrome related to COVID-19 infection. Neurol Neuroimmunol Neuroinflamm. 2020;7:e741. https://doi. org/10.1212/NXI.0000000000000741.

3. Montalvan V, Lee J, Bueso T, de Toledo J, Rivas K. Neurological manifestations of COVID-19 and other coronavirus infections: a systematic review. Clin Neurol Neurosurg. 2020;194:105921. https://doi.org/10.1016/j.clineuro.2020.105921.

4. Dalakas MC. Guillain-Barré syndrome: the first documented COVID-19-triggered autoimmune neurologic disease: more to come with myositis in the offing. Neurol Neuroimmunol Neuroinflamm. 2020;7:e781. https://doi.org/10.1212/NXI. 0000000000000781.

5. Costello F, Dalakas MC. Cranial neuropathies and COVID-19: neurotropism and autoimmunity. Neurology. 2020. https://doi.org/ 10.1212/WNL.0000000000009921.

6. Petersen E, Koopmans M, Go U, Hamer DH, Petrosillo N, Castelli F, et al. Comparing SARS-CoV-2 with SARS-CoV and influenza pandemics. Lancet Infect Dis. 2020;20:e238-44. https://doi.org/10. 1016/S1473-3099(20)30484-9.

7. Mao L, Wang M, Chen S, et al. Neurological manifestations of hospitalized patients with COVID-19 in Wuhan, China: a retrospective case series study. SSRN Electron J. 2020:93-122. https:// doi.org/10.1101/2020.02.22.20026500.

8. Ottaviani D, Boso F, Tranquillini E, Gapeni I, Pedrotti G, Cozzio S, et al. Early Guillain-Barré syndrome in coronavirus disease 2019 (COVID-19): a case report from an Italian COVID-hospital. Neurol Sci. 2020;41:1351-4. https://doi.org/10.1007/s10072-020-044498.

9. Marta-Enguita J, Rubio-Baines I, Gastón-Zubimendi I. Fatal Guillain-Barre syndrome after infection with SARS-CoV-2. Neurol (Engl Ed). 2020;35:265-7. https://doi.org/10.1016/j. nrleng.2020.04.004.

10. Seneviratne U. Guillain-Barré syndrome. Postgrad Med. 2000;76: 774-82.

11. Juliao Caamaño DS, Alonso Beato R. Facial diplegia, a possible atypical variant of Guillain-Barré syndrome as a rare neurological complication of SARS-CoV-2. J Clin Neurosci. 2020;77:230-2. https://doi.org/10.1016/j.jocn.2020.05.016.

12. Benvenuto A, Carella AM, Conte M, et al. Atypical clinical presentation of COVID-19: a case of Guillain-Barrè Syndrome related to SARS-Cov-2 infection. Curr Trends Clin Med Sci. 2020;2. https:// doi.org/10.33552/CTCMS.2020.02.000526.

13. Yuki N, Hartung H. Guillain-Barré Syndrome. N Engl J Med. 2012;366:2294-304. https://doi.org/10.1056/NEJMra1114525.

14. Wen W, Su W, Tang H, le W, Zhang X, Zheng Y, et al. Immune cell profiling of COVID-19 patients in the recovery stage by singlecell sequencing. Cell Discov. 2020;6:31. https://doi.org/10.1038/ s41421-020-0168-9.

15. Lucchese G, Flöel A. SARS-CoV-2 and Guillain-Barré syndrome: molecular mimicry with human heat shock proteins as potential pathogenic mechanism. Cell Stress Chaperones. 2020;25:731-5. https://doi.org/10.1007/s12192-020-01145-6.

16. Wim Ang C, Jacobs BC, Laman JD. The Guillain-Barré syndrome: a true case of molecular mimicry. Trends Immunol. 2004;25:61-6. https://doi.org/10.1016/j.it.2003.12.004.

17. Furukawa K, Ohmi Y, Yesmin F, Tajima O, Kondo Y, Zhang P, et al. Novel molecular mechanisms of gangliosides in the nervous system elucidated by genetic engineering. Int J Mol Sci. 2020;21. https://doi.org/10.3390/ijms21061906.

18. Cutillo G, Saariaho A-H, Meri S. Physiology of gangliosides and the role of antiganglioside antibodies in human diseases. Cell Mol Immunol. 2020;17:313-22. https://doi.org/10.1038/s41423-0200388-9.

19. Yu RK, Usuki S, Ariga T. Ganglioside molecular mimicry and its pathological roles in Guillain-Barré syndrome and related diseases. Infect Immun. 2006;74:6517-27. https://doi.org/10.1128/IAI. 00967-06.

20. Sung EJ, Kim DY, Chang MC, Ko EJ. Prediction of functional outcome in axonal Guillain-Barre syndrome. Ann Rehabil Med. 2016;40:481-8. https://doi.org/10.5535/arm.2016.40.3.481.

21. Perrotta F, Matera MG, Cazzola M, Bianco A. Severe respiratory SARS-CoV2 infection: does ACE2 receptor matter? Respir Med. 2020;168:105996. https://doi.org/10.1016/j.rmed.2020.105996. 
22. Dinkin M, Gao V, Kahan J, et al. COVID-19 presenting with ophthalmoparesis from cranial nerve palsy. Neurology. 2020. https://doi.org/10.1212/WNL.0000000000009700.

23. Natoli S, Oliveira V, Calabresi P, et al. Does SARS-Cov-2 invade the brain? Translational lessons from animal models. Eur J Neurol. 2020:1-10. https://doi.org/10.1111/ene.14277.

24. Whittaker A, Anson M, Harky A. Neurological manifestations of COVID-19: a review. Acta Neurol Scand. 2020;11:1-9. https://doi. org/10.1111/ane.13266.

25. van Doorn PA, Ruts L, Jacobs BC. Clinical features, pathogenesis, and treatment of Guillain-Barré syndrome. Lancet Neurol. 2008;7: 939-50. https://doi.org/10.1016/S1474-4422(08)70215-1.

26. McGrogan A, Madle GC, Seaman HE, de Vries CS. The epidemiology of Guillain-Barré syndrome worldwide: a systematic literature review. Neuroepidemiology. 2009;32:150-63. https://doi.org/ 10.1159/000184748

27. Amatya B, Khan F, Whishaw M, Pallant JF. Guillain-Barré syndrome: prevalence and long-term factors impacting bladder function in an Australian community cohort. J Clin Neurol. 2013;9:144 50. https://doi.org/10.3988/jcn.2013.9.3.144.

28. Meythaler JM. Rehabilitation of Guillain-Barré syndrome. Arch Phys Med Rehabil. 1997;78:872-9. https://doi.org/10.1016/ s0003-9993(97)90203-3.

29. Garg M. Respiratory involvement in Guillain-Barre syndrome: the uncharted road to recovery. J Neurosci Rural Pract. 2017;8:325-6. https://doi.org/10.4103/jnrp.jnrp 96 17R1.

30. Lawn ND, Fletcher DD, Henderson RD, Wolter TD, Wijdicks EFM. Anticipating mechanical ventilation in Guillain-Barré syndrome. Arch Neurol. 2001;58:893-8. https://doi.org/10.1001/ archneur.58.6.893.

31. Zhao H, Shen D, Zhou H, Liu J, Chen S. Guillain-Barré syndrome associated with SARS-CoV-2 infection: causality or coincidence? Lancet Neurol. 2020;19:383-4. https://doi.org/10.1016/S14744422(20)30109-5.

32. Sedaghat Z, Karimi N. Guillain Barre syndrome associated with COVID-19 infection: a case report. J Clin Neurosci. 2020;76: 233-5. https://doi.org/10.1016/j.jocn.2020.04.062.

33. Kim JE, Heo JH, Kim HO, Song SH, Park SS, Park TH, et al. Neurological complications during treatment of middle east respiratory syndrome. J Clin Neurol. 2017;13:227-33. https://doi.org/ 10.3988/jen.2017.13.3.227.

34. Willison HJ, Jacobs BC, van Doorn PA. Guillain-Barré syndrome. Lancet. 2016;388:717-27. https://doi.org/10.1016/S0140-6736(16) 00339-1.

35. Asbury AK, Cornblath DR. Assessment of current diagnostic criteria for Guillain-Barré syndrome. Ann Neurol. 1990;27(Suppl):S21-4. https://doi.org/10.1002/ana.410270707.

36. Riva N, Russo T, Falzone YM, et al. Post-infectious Guillain-Barré syndrome related to SARS-CoV-2 infection: a case report. J Neurol. 2020:4-6. https://doi.org/10.1007/s00415-020-09907-z.

37. Toscano G, Palmerini F, Ravaglia S, et al. Guillain-Barré syndrome associated with SARS-CoV-2. N Engl J Med. 2020: NEJMc2009191. https://doi.org/10.1056/NEJMc2009191.

38. Padroni M, Mastrangelo V, Asioli GM, et al. Guillain-Barré syndrome following COVID-19: new infection, old complication? J Neurol. 2020:1-3. https://doi.org/10.1007/s00415-020-09849-6.

39. Assini A, Benedetti L, Di Maio S, et al. New clinical manifestation of COVID-19 related Guillain-Barrè syndrome highly responsive to intravenous immunoglobulins: two Italian cases. Neurol Sci. 2020;41:2307. https://doi.org/10.1007/s10072-020-04517-z.

40. Coen M, Jeanson G, Culebras Almeida LA, et al. Guillain-Barré syndrome as a complication of SARS-CoV-2 infection. Brain Behav Immunol. 2020:1-2. https://doi.org/10.1016/j.bbi.2020.04. 074.

41. Agosti E, Giorgianni A, D’Amore F, Vinacci G, Balbi S, Locatelli D. Is Guillain-Barrè syndrome triggered by SARS-CoV-2? Case report and literature review. Neurol Sci. 2020. https://doi.org/10. 1007/s10072-020-04553-9.

42. Gutiérrez-Ortiz C, Méndez A, Rodrigo-Rey S, et al. Miller Fisher syndrome and polyneuritis cranialis in COVID-19. Neurology. 2020;241. https://doi.org/10.1212/WNL.0000000000009619.

43. Sancho-Saldaña A, Lambea-Gil Á, Liesa JLC, et al. Guillain-Barré syndrome associated with leptomeningeal enhancement following SARS-CoV-2 infection. Clin Med (Northfield Il). 2020;20. https:// doi.org/10.7861/clinmed.2020-0213.

44. Velayos Galán A, del Saz Saucedo P, Peinado Postigo F, et al. Guillain-Barré syndrome associated with SARS-CoV-2 infection. Neurol (Engl Ed). 2020;35:268-9. https://doi.org/10.1016/j.nrleng. 2020.04.006.

45. Guijarro-Castro C, Rosón-González M, Abreu A, García-Arratibel A, Ochoa-Mulas M. Guillain-Barré syndrome associated with SARS-CoV-2 infection. Comments after 16 published cases. Neurologia. 2020;35:412-5. https://doi.org/10.1016/j.nrl.2020.06. 002.

46. Diez-Porras L, Vergés E, Gil F, Vidal MJ, Massons J, Arboix A. Guillain-Barré-Strohl syndrome and COVID-19: case report and literature review. Neuromuscul Disord. 2020;30:859-61. https:// doi.org/10.1016/j.nmd.2020.08.354.

47. Chan M, Han SC, Kelly S, et al. A case series of Guillain-Barré syndrome following Covid-19 infection in New York. Neurol Clin Pract. 2020. https://doi.org/10.1212/CPJ.0000000000000880, https://doi.org/10.1212/CPJ.0000000000000880.

48. Lantos JE, Strauss SB, Lin E. COVID-19-associated Miller Fisher syndrome: MRI findings. Am J Neuroradiol. 2020;41:1184-6. https://doi.org/10.3174/ajnr.A6609.

49. Rana S, Lima AA, Chandra R, Valeriano J, Desai T, Freiberg W, et al. Novel coronavirus (COVID-19)-associated Guillain-Barré syndrome: case report. J Clin Neuromuscul Dis. 2020;21:240-2. https://doi.org/10.1097/CND.0000000000000309.

50. Virani A, Rabold E, Hanson T, Haag A, Elrufay R, Cheema T, et al. Guillain-Barré syndrome associated with SARS-CoV-2 infection. IDCases. 2020;20:e00771. https://doi.org/10.1016/j.idcr.2020. e00771.

51. Naddaf E, Laughlin RS, Klein CJ, Toledano M, Theel ES, Binnicker MJ, et al. Guillain-Barré syndrome in a patient with evidence of recent SARS-CoV-2 infection. Mayo Clin Proc. 2020;95:1799-801. https://doi.org/10.1016/j.mayocp.2020.05. 029 .

52. Abrams RMC, Kim BD, Markantone DM, et al. Severe rapidly progressive Guillain-Barré syndrome in the setting of acute COVID-19 disease. J Neurovirol. 2020:3-5. https://doi.org/10. 1007/s13365-020-00884-7.

53. Su XW, Palka SV, Rao RR, Chen FS, Brackney CR, Cambi F. SARS-CoV-2-associated Guillain-Barré syndrome with dysautonomia. Muscle Nerve. 2020;62:E48-9. https://doi.org/10. 1002/mus.26988.

54. Ebrahimzadeh SA, Ghoreishi A, Rahimian N. Guillain-Barré syndrome associated with the coronavirus disease 2019 (COVID-19). Neurol Clin Pract. 2020;2019. https://doi.org/10.1212/CPJ. 0000000000000879 , https://doi.org/10.1212/cpj. 0000000000000879.

55. Paybast S, Gorji R, Mavandadi S. Guillain-Barré syndrome as a neurological complication of novel COVID-19 infection: a case report and review of the literature. Neurologist. 2020;25:101-3. https://doi.org/10.1097/NRL.0000000000000291.

56. Farzi MA, Ayromlou H, Jahanbakhsh N, Bavil PH, Janzadeh A, Shayan FK. Guillain-Barré syndrome in a patient infected with SARS-CoV-2, a case report. J Neuroimmunol. 2020;346:577294. https://doi.org/10.1016/j.jneuroim.2020.577294.

57. Scheidl E, Canseco DD, Hadji-Naumov A, et al. Guillain-Barré syndrome during SARS-CoV-2 pandemic: a case report and review 
of recent literature. J Peripher Nerv Syst. 2020. https://doi.org/10. 1111/jns. 12382.

58. Pfefferkorn T, Dabitz R, von Wernitz-Keibel T, et al. Acute polyradiculoneuritis with locked-in syndrome in a patient with Covid-19. J Neurol. 2020:19-20. https://doi.org/10.1007/s00415020-09897-y.

59. Pfeuffer S, Pawlowski M, Joos GS, Minnerup J, Meuth SG, Dziewas R, et al. Autoimmunity complicating SARS-CoV-2 infection in selective IgA-deficiency. Neurol Neuroimmunol Neuroinflamm. 2020;7:e881. https://doi.org/10.1212/NXI. 0000000000000881.

60. Webb S, Wallace VC, Martin-Lopez D, et al. Guillain-Barré syndrome following COVID-19: a newly emerging post-infectious complication. BMJ Case Rep. 2020;13:1-4. https://doi.org/10. 1136/bcr-2020-236182.

61. Tiet MY, Alshaikh N. Guillain-Barré syndrome associated with COVID-19 infection: a case from the UK. BMJ Case Rep. 2020;13:1-4. https://doi.org/10.1136/bcr-2020-236536.

62. Ray A. Miller Fisher syndrome and COVID-19: is there a link? BMJ Case Rep. 2020;13:e236419. https://doi.org/10.1136/bcr2020-236419.

63. Arnaud S, Budowski C, Ng Wing Tin S, Degos B. Post SARSCoV-2 Guillain-Barré syndrome. Clin Neurophysiol. 2020;131: 1652-4. https://doi.org/10.1016/j.clinph.2020.05.003.

64. Camdessanche J-P, Morel J, Pozzetto B, Paul S, Tholance Y, Botelho-Nevers E. COVID-19 may induce Guillain-Barré syndrome. Rev Neurol (Paris). 2020;176:516-8. https://doi.org/10. 1016/j.neurol.2020.04.003.

65. Bigaut K, Mallaret M, Baloglu S, Nemoz B, Morand P, Baicry F, et al. Guillain-Barré syndrome related to SARS-CoV-2 infection. Neurol Neuroimmunol Neuroinflamm. 2020;7:e785. https://doi. org/10.1212/NXI.0000000000000785.

66. Chan JL, Ebadi H, Sarna JR. Guillain-Barré syndrome with facial diplegia related to SARS-CoV-2 infection. Can J Neurol Sci. 2020: 1-3. https://doi.org/10.1017/cjn.2020.106.

67. El Otmani H, El Moutawakil B, Rafai M-A, et al. Covid-19 and Guillain-Barré syndrome: more than a coincidence! Rev Neurol (Paris). 2020;176:518-9. https://doi.org/10.1016/j.neurol.2020.04. 007.

68. Lehmann HC, MacHt S, Jander S, et al. Guillain-Barré syndrome variant with prominent facial diplegia, limb paresthesia, and brisk reflexes. J Neurol. 2012;259:370-1. https://doi.org/10.1007/ s00415-011-6169-8.

69. Susuki K, Koga M, Hirata K, Isogai E, Yuki N. A Guillain-Barré syndrome variant with prominent facial diplegia. J Neurol. 2009;256:1899-905. https://doi.org/10.1007/s00415-009-5254-8.

70. Gupta A, Paliwal VK, Garg RK. Is COVID-19-related GuillainBarré syndrome different? Brain Behav Immun. 2020;87:177-8. https://doi.org/10.1016/j.bbi.2020.05.051.

71. Meena AK, Archana AD, Reddy GC, Ramakrishn D, Rao P. Antiganglioside antibodies in sub types of Guillain-Barre syndrome in an Indian population. J Med Sci. 2010;10:138-42. https://doi. org/10.3923/jms.2010.138.142.

72. Kim JK, Kim YH, Yoon BA, Cho JY, Oh SY, Shin HY, et al. Clinical heterogeneity of anti-GM2-ganglioside-antibody syndrome. J Clin Neurol. 2018;14:401-6. https://doi.org/10.3988/jen. 2018.14.3.401.

73. Rogers JP, Chesney E, Oliver D, Pollak TA, McGuire P, Fusar-Poli $\mathrm{P}$, et al. Psychiatric and neuropsychiatric presentations associated with severe coronavirus infections: a systematic review and meta- analysis with comparison to the COVID-19 pandemic. Lancet Psychiatry. 2020;7:611-27. https://doi.org/10.1016/S22150366(20)30203-0.

74. Martinotti G, Barlati S, Prestia D, Palumbo C, Giordani M, Cuomo A, et al. Psychomotor agitation and hyperactive delirium in COVID-19 patients treated with aripiprazole $9.75 \mathrm{mg} / 1.3 \mathrm{ml}$ immediate release. Psychopharmacology. 2020;237:3497-501. https:// doi.org/10.1007/s00213-020-05644-3.

75. Li Z, Liu T, Yang N, et al. Neurological manifestations of patients with COVID-19: potential routes of SARS-CoV-2 neuroinvasion from the periphery to the brain. Front Med. 2020. https://doi.org/10. 1007/s11684-020-0786-5.

76. Doets AY, Verboon C, van den Berg B, Harbo T, Cornblath DR, Willison HJ, et al. Regional variation of Guillain-Barré syndrome. Brain. 2018;141:2866-77. https://doi.org/10.1093/brain/awy232.

77. Parra B, Lizarazo J, Jiménez-Arango JA, Zea-Vera AF, GonzálezManrique G, Vargas J, et al. Guillain-Barré syndrome associated with Zika virus infection in Colombia. N Engl J Med. 2016;375: 1513-23. https://doi.org/10.1056/NEJMoa1605564.

78. Voinsky I, Baristaite G, Gurwitz D. Effects of age and sex on recovery from COVID-19: analysis of 5769 Israeli patients. J Infect. 2020:19-21. https://doi.org/10.1016/j.jinf.2020.05.026.

79. Sahin S, Cinar N, Karsidag S. Are cerebrospinal fluid protein levels and plasma neutrophil/lymphocyte ratio associated with prognosis of Guillain Barré syndrome? Neurol Int. 2017;9:7276. https://doi. org/10.4081/ni.2017.7032.

80. Domingues RB, Fernandes GBP, de Moura Leite FBV, et al. The cerebrospinal fluid in multiple sclerosis: far beyond the bands. Einstein (Sao Paulo). 2017;15:100-4. https://doi.org/10.1590/ S1679-45082017RW3706.

81. Lo YL. Clinical and immunological spectrum of the Miller Fisher syndrome. Muscle Nerve. 2007;36:615-27. https://doi.org/10. 1002/mus.20835.

82. Steininger C, Popow-Kraupp T, Seiser A, Gueler N, Stanek G, Puchhammer E. Presence of cytomegalovirus in cerebrospinal fluid of patients with guillain-barré syndrome. J Infect Dis. 2004;189: 984-9. https://doi.org/10.1086/382192.

83. Kuijf ML, Ang CW, van Doorn PA, Niesters HGM, Jacobs BC. Presence or absence of cytomegalovirus in cerebrospinal fluid from patients with Guillain-Barré syndrome? J Infect Dis. 2006;193: 1471-2; author reply 1472-3. https://doi.org/10.1086/503440.

84. Moriguchi T, Harii N, Goto J, Harada D, Sugawara H, Takamino J, et al. A first case of meningitis/encephalitis associated with SARSCoronavirus-2. Int J Infect Dis. 2020;94:55-8. https://doi.org/10. 1016/j.ijid.2020.03.062.

85. Paniz-Mondolfi A, Bryce C, Grimes Z, et al. Central nervous system involvement by severe acute respiratory syndrome coronavirus -2 (SARS-CoV-2). J Med Virol. 2020;2. https://doi.org/10.1002/ jmv.25915.

86. Panciani PP, Saraceno G, Zanin L, Renisi G, Signorini L, Battaglia L, et al. SARS-CoV-2: "three-steps" infection model and CSF diagnostic implication. Brain Behav Immun. 2020;87:128-9. https:// doi.org/10.1016/j.bbi.2020.05.002.

87. Wang W, Xu Y, Gao R, Lu R, Han K, Wu G, et al. Detection of SARS-CoV-2 in different types of clinical specimens. JAMA. 2020;323:1061-9. https://doi.org/10.1001/jama.2020.3786.

Publisher's Note Springer Nature remains neutral with regard to jurisdictional claims in published maps and institutional affiliations. 